\title{
Operative Gynecologic Endoscopy
}

Springer Science+Business Media, LLC 


\section{$\frac{\mathrm{CP}}{\mathrm{OB} / \mathrm{GYN}}$}

\section{Clinical Perspectives in Obstetrics and Gynecology}

Series Editor: Isaac Schiff, M.D.

Published Volumes:

Shoupe and Haseltine (eds.): Contraception (1993)

Lorrain (ed.): Comprehensive Management of

Menopause (1993)

Gonik (ed.): Viral Diseases in Pregnancy (1994)

Flamm and Quilligan (eds.): Cesarean Section:

Guidelines for Appropriate Utilization (1995)

Forthcoming Volumes:

Reindollar and Gray (eds.): Molecular Biology for the

Obstetrician-Gynecologist

Stovall and Guido (eds.): Acute Care Gynecology

Published Volumes (Series Editor: The Late

Herbert J. Buchsbaum, M.D.):

Buchsbaum (ed.): The Menopause (1983)

Aiman (ed.): Infertility (1984)

Futterweit: Polycystic Ovarian Disease (1984)

Lavery and Sanfilippo (eds.): Pediatric and Adolescent

Obstetrics and Gynecology (1985)

Galask and Larson (eds.): Infectious Diseases in the

Female Patient (1986)

Buchsbaum and Walton (eds.): Strategies in

Gynecologic Surgery (1986)

Szulman and Buchsbaum (eds.): Gestational Trophoblastic

Disease (1987)

Cibils (ed.): Surgical Diseases in Pregnancy (1990)

Collins (ed.): Ovulation Induction (1990)

Sanfilippo and Levine (eds.): Operative Gynecologic

Endoscopy (1990)

Altchek and Deligdisch (eds.): The Uterus (1991) 


\section{Joseph S. Sanfilippo, M.D. Ronald L. Levine, M.D.}

Department of Obstetrics and Gynecology University of Louisville School of Medicine

Editors

\section{Operative Gynecologic Endoscopy Second Edition}

With 321 black and white illustrations and 55 color plates

Foreword by Byron J. Masterson, M.D. 
Editors:

Joseph S. Sanfilippo, M.D. \&onald L. Levine, M.D.

Department of Obstetrics and Gynecology, University of Louisville School of Medicine, Louisville, KY 40292, USA

Library of Congress Cataloging-in-Publication Data

Operative gynecologic endoscopy / Joseph S. Sanfilippo, Ronald L. Levine, editors. - 2nd ed.

p. cm. - (Clinical perspectives in obstetrics and gynecology)

Includes bibliographical references and index.

ISBN 978-1-4612-7505-3

ISBN 978-1-4612-2330-6 (eBook)

DOI 10.1007/978-1-4612-2330-6

1. Generative organs, Female-Endoscopic surgery. I. Sanfilippo, J. S. (Joseph S.) II. Levine, R. L. (Ronald L.) III. Series.

[DNLM: 1. Genitalia, Female—surgery. 2. Laser Surgery. 3. Endoscopy. WP 660061 1996]

RG104.7.0635 1996

618.1'059-dc20

DNLM/DLC

for Library of Congress

95-25735

Printed on acid-free paper.

() 1996, 1989 Springer Science+Business Media New York

Originally published by Springer-Verlag New York, Inc. in 1996

Softcover reprint of the hardcover 1st edition 1996

All rights reserved. This work may not be translated or copied in whole or in part without the written permission of the publisher (Springer-Verlag New York, Inc., 175 Fifth Avenue, New York, NY 10010, USA), except for brief excerpts in connection with reviews or scholarly analysis. Use in connection with any form of information storage and retrieval, electronic adaptation, computer software, or by similar or dissimilar methodology now known or hereafter developed is forbidden.

The use of general descriptive names, trade names, trademarks, etc., in this publication, even if the former are not especially identified, is not to be taken as a sign that such names, as understood by the Trade Marks and Merchandise Marks Act, may accordingly be used freely by anyone.

While the advice and information in this book are believed to be true and accurate at the date of going to press, neither the authors nor the editors nor the publisher can accept any legal responsibility for any errors or omissions that may be made. The publisher makes no warranty, express or implied, with respect to the material contained herein.

Production managed by Robert Wexler; manufacturing supervised by Jacqui Ashri.

Typeset by Princeton Editorial Associates, Inc., Princeton, NJ.

9876554321 
We dedicate this book to our families for their patience and to our patients, whom we care for as family. 


\section{Foreword}

While the technical development of pelvic endoscopy began in the late 1800s and early 1900s, its wider application in the United States occurred during the 1960s. The principal procedures were diagnostic or tubal interruption. Where the instrument maker and instrument user were closely aligned, creative solutions to surgical problems began to appear. Dr. Kurt Semm and other members of his family business were most innovative, and physicians from around the world began to visit him at the Christian Albrechts University in Kiel, Germany. They returned home with a new appreciation of what could be accomplished in the abdominal cavity via the endoscope. Many of the early procedures in gynecology that did not necessarily merit a laparotomy were worth the minimally invasive approach, and studies assessing cost of a laparoscopic procedure and additional information in the areas of pelvic pain management, endometriosis, and infertility were reported.

In 1986, the University of Louisville hosted the first university course in operative laparoscopy given in the United States. The faculty members were prominent in the conference that facilitated the aggressive adoption of the expanded view of pelvic endoscopy. Standards of technical excellence for endoscopic surgery soon developed. Just as the first bilateral ovarian tumor removal in Kentucky spawned a whole era of abdominal gynecologic surgery, many new operative procedures, techniques, and instruments sprang from an expanding array of creative and energetic minds. The first studies of appropriate suture materials (endoloops), knot strengths, and other technical advances in endoscopic surgery were conducted in the Wound Laboratory at the University of Louisville Department of Obstetrics and Gynecology. The investment necessary for the development, purchase, and maintenance of the very highly successful technical innovations in a commercially acceptable environment was due to the long term vision of the administration of the University of Louisville affiliated hospitals Alliant Health System and Jewish Hospital. Making these innovations commercially acceptable was and is a significant advance. One of the earliest studies on cost accounting of these procedures was published by Dr. Ronald Levine. The very careful and critical future analysis of miniaturization, virtual reality, multimodal imaging and molecular manipulation of the disease processes found 
endoscopic surgery to hold great promise for the future. I look forward most enthusiastically to the leadership of Drs. Sanfilippo and Levine, as well as the physicians they have trained in this new and exciting era in gynecologic surgery.

Byron J. Masterson, M.D.

J. Wayne Reitz Professor of Gynecologic Surgery

Co-Director, Wound Institute

University of Florida 


\section{Preface}

Our first edition of Operative Gynecologic Endoscopy, published in 1989, included what seemed at that time to be revolutionary ideas of laparoscopic and hysteroscopic gynecologic surgery. The preface to that edition contained the well-known quote from Dr. Alan DeCherney (Fertil Steril 1985;44:299): “The obituary of pelvic reconstructive surgery has been written: it is only its publication that remains." His view of the future was remarkably clear, as operative endoscopic surgery has indeed supplanted laparotomy in a great proportion of gynecologic operations.

We were convinced then, and our belief has been reaffirmed, that operative endoscopy would contribute significantly to the enhancement of health care for women. Our prediction of decreased costs of this modality has been altered only by widespread and often injudicious use of disposable instruments and by inappropriately high charges by some health care providers. Even so, the impact of this technique on the total health care economics of the United States is startling in its potential. The return of women to the workplace 10 days to 3 weeks earlier than if they had a laparotomy must impress most observers and has particular importance to industry.

In 1988 the American Association of Gynecologic Laparoscopists (AAGL) survey of more than 800 physicians demonstrated that operative endoscopic procedures fell mainly in the area of laser vaporization of endometrial implants, lysis of adhesions, ovarian cystectomy, surgical treatment of ectopic pregnancy, tuboplasty, myomectomy, and management of pelvic abscesses. Multiple operative laparoscopic procedures were performed by the respondents with a "serious complication rate" of 15.4 per 1000 procedures. In a 1993 survey the complication rate appeared to be similar to that in a previous report (1991) but with a clear increase in the number of unintended laparotomies, hemorrhage, and gastrointestinal and urinary tract injuries (J Am Assoc Gyn Laparosc 1995; 2:134).

Similarly, operative hysteroscopic procedures have taken on a new dimension. In 1988 a hysteroscopic complication rate (most frequently uterine perforation not requiring transfusion) of 13 per 1000 procedures was reported. In 1993 a complication rate of 14.2 per 1000 was reported, including uterine perforations, hyponatre- 
mia in association with water intoxication, pulmonary edema, and a number of other complications: hospital readmission, transfusion requirement, laparotomy, neurologic injury, and gastrointestinal and genitourinary tract injuries.

This wealth of experience enables clinicians to determine the risk/benefit ratio preoperatively, identify and manage intraoperative complications, and perhaps most importantly offer patients technologic advances in the field of endoscopic surgery. Thus we have embarked on the second edition of our textbook. It provides clinicians with an update regarding instrumentation, current knowledge of electrosurgical principles, new laser technology, and procedures to avoid bowel and ureteral injury and postoperative problems.

The contributors to this edition include many of the original chapter authors, most of whom were among the pioneers of operative endoscopy. They obviously have the depth and breadth of knowledge and the clinical experience to enhance the usefulness of this text. Several of the contributors were on the faculty of the first American university-sponsored course on operative laparoscopy that was held in Louisville, Kentucky in April 1986. All of the present contributors have great experience in teaching both laparoscopic and endoscopic surgery.

Clinicians must realize that technologic advances afford us the opportunity to offer patients a number of alternatives to open surgery, including endoscopic vaginal reconstruction, new approaches to management of acute pelvic inflammatory disease, laparoscopic-assisted hysterectomy, the Classic Assisted SEMM Hysterectomy (CASH) procedure, the laparoscopic Burch procedure and vaginal suspension. These techniques are of increasing importance in pediatric adolescent gynecology. Increasingly gynecologists are called upon to assist their surgical colleagues when dealing with such entities as laparoscopic lymphadenectomy and laparoscopic intervention in the pregnant patient as well as in pediatric laparoscopy.

The Council on Resident Education in Obstetrics and Gynecology (CREOG) has embarked on an intensive effort to provide clinicians with defined goals and objectives when teaching endoscopic surgery to residents. Included are cognitive and technical objectives to ensure the competence of these residents in specific areas.

Rapid advances in the arena of operative hysteroscopy continues to enhance our clinical acumen. Management of abnormal uterine bleeding with endometrial ablation, current techniques with respect to hysteroscopic myomectomy, and ultrasonographic Doppler flow studies also provide us with new vistas regarding preoperative and intraoperative management of specific endoscopic surgical procedures. As we come full circle, fetal endoscopic surgery takes on a new dimension. Clinical perspectives beyond the year 2000 must be kept in mind. Innovations in instrumentation and technology have set the stage for the second edition of our textbook Operative Gynecologic Endoscopy. 


\section{Acknowledgments}

We are indebted to Alliant Health System and Jewish Hospital, for their generous support in making this book possible. We owe special thanks to our former colleague, now retired, Douglas M. Haynes, M.D., for his translation of Professor Kurt Semm's chapter on history and for his many years of scholarly guidance. We are greatly appreciative to the University of Louisville School of Medicine for continuing its tradition of excellence in teaching and research and for providing us the environment and encouragement to see our ideas and goals become reality. Thanks also must go to our secretarial staff and our editorial assistant Ms. Leta Weedman for their help and unending enthusiasm to see this text through to completion. Most importantly, we acknowledge the support and guidance of our wives, Patricia and Sonia, and our families. Once again, we thank them not only for their help and forbearance but most importantly for understanding the demands of our "mistress medicine." 


\section{Contents}

Foreword

vii

BYRON J. MASTERSON

Preface

ix

JOSEPH S. SANFILIPPO and RONALD L. LEVINE

Acknowledgments

Contributors

Section I History

1. History

KURT SEMM, translated by DOUGLAS M. HAYNES

\section{Section II Instrumentation}

2. Instrumentation

RONALD L. LEVINE

3. Lasers

ANTHONY A. LUCIANO

4. Electrosurgery

ROGER C. O'DELL

5. Documentation

JOHN M. LEVENTHAL

\section{Section III Laparoscopic Techniques}

6. Laparoscopic Myomectomy HARRITH M. HASSON

7. Ovarian Surgery

RONALD L. LEVINE

8. Laparoscopic-Assisted Hysterectomy: American Perspective

C. Y. LIU and D. AlAN JOHNS 
9. Pelviscopic Intrafascial Hysterectomy Without Colpotomy PAUL F. VIETZ

10. Vaginal Prolapse and Bladder Suspension: Role of Endoscopic Surgery

C. Y. LIU

11. Ectopic Pregnancy

DWIGHT PRIDHAM and HARRY REICH

12. Distal Tubal Reconstructive Surgery

LISA PEACOCK and JOHN A. ROCK

13. Laparoscopic Tubal Reanastomosis

D. AlAN JOHNS

14. Endometriosis

DAVID B. REDWINE

15. Laparoscopic Treatment of Tuboovarian and Pelvic Abscess HARRY REICH and F. MichaEL SHAW

16. Laparoscopic Pelvic Lymph Node Dissection for Urologic

Malignancies

J. MATTHEW GLASCOCK and HOWARD WINFIELD

17. Endoscopic Surgical Procedures During Pregnancy

MARCELlo PIETRANTONI and JosePH S. SANFILIPPO

18. Principles of Pediatric Laparoscopy

JOSEPH S. SANFILIPPO and THOM E. LOBE

19. Laparoscopic Suturing Techniques

HOWARD C. TOPEL

20. Assisted Reproductive Technology Versus Tubal Surgery

Claudio A. Benadiva, IsaAC Kligman, and ZeV RosenWaKs

21. Current Perspectives LOTHAR W. POPP

\section{Section IV Hysteroscopic Techniques}

22. Operative Hysteroscopy and Resectoscopy RAFAEL F. VALLE

23. Abnormal Uterine Bleeding and Endometrial Ablation RICHARD J. GIMPELSON

\section{Section V Supportive Techniques and Procedures}

24. Anesthesia

LINDA F. LUCAS and BENJAMIN M. RIGOR

25. Complications

26. Adhesion Prevention and Lysis: Indications for Laparotomy and

Laparoscopy

MiCHAEL P. DIAMOND and ESAT ORHON

27. Role of Pelvic Ultrasonography and Color Doppler in Laparoscopy 404 RESAD PASIC

28. Operating Room Personnel WENDY K. WINER

29. Teaching Operative Endoscopy 
30. Learning, Certification, and Credentialing for Endoscopic Surgery CARL J. LEVINSON and RAYMOND H. KAUFMAN

31. Legal Issues Regarding Operative Gynecologic Endoscopy STEVEN R. SMITH

\section{Section VI General Surgery and New Horizons}

32. Laparoscopic Overview: General Surgery Perspective GARY C. VITALE

33. Fetus as an Endoscopic Surgical Patient

RUBÉN A. QUINTERO

34. Clinical Perspectives: The Year 2000

PATRICK J. TAYLOR

Index 


\section{Contributors}

Claudio Benadiva, M.D., Center for Fertility and Reproductive Endocrinology, New Britain General Hospital, New Britain, CT 06050, USA

MiChAEL P. DiAmOND, M.D., Division of Reproductive Endocrinology and Infertility, Departments of Obstetrics and Gynecology, and Physiology, Wayne State University, Detroit, MI 48201, USA

RICHARD J. GIMPELSON, M.D., Department of Obstetrics and Gynecology, St. Louis University School of Medicine, St. Louis, MO 63110, USA

J. MATTHEW GLASCOCK, M.D., Department of Urology, The University of Iowa College of Medicine, Iowa City, IA 52242-1101, USA

HARRITH M. HASSON, M.D., University of Chicago Hospitals, Gynecologic Endoscopy Center at Weiss Memorial Hospital, Chicago IL 60640, USA

D. ALAN JoHNs, M.D., Richland Medical Center, Fort Worth, TX 76180, USA

RaYmond H. Kaufman, M.D., Department of Obstetrics and Gynecology, Texas Medical Center, Baylor College of Medicine, Houston, TX 77030-3498, USA

ISAAC KLIGMAN, M.D., Center for Fertility and Reproductive Endocrinology, New Britain General Hospital, New Britain CT 06050, USA

JoHN M. LeVENTHAL, M.D., Department of Obstetrics and Gynecology, Harvard Medical School, Boston, MA 02120, USA

Ronald L. LeVINE, M.D., Department of Obstetrics and Gynecology, University of Louisville School of Medicine, Louisville KY 40292, USA 
Carl J. LeVinson, M.D., Department of Obstetrics and Gynecology, Stanford University School of Medicine, Stanford CA 94305-5317, USA

BARbara S. LEVy, M.D., Department of Obstetrics and Gynecology, University of Washington School of Medicine, Seattle WA 98195, USA

C.Y. LIU, M.D., Chattanooga Women's Laser Center, Chattanooga, TN 37421, USA

Thom E. LOBE, M.D., Section of Pediatric Surgery, University of Tennessee, Memphis, Memphis, TN 38163, USA

LINDA F. LUCAS, M.D., Department of Anesthesiology, University of Louisville School of Medicine, Louisville, KY 40292, USA

ANTHONY A. LuCIANO, M.D., Department of Obstetrics and Gynecology, University of Connecticut School of Medicine, Farmington, CT 06030, and Center for Fertility and Reproductive Endocrinology, New Britain General Hospital, New Britain, CT 06050, USA

ROGER C. ODELL, Electroscope, Inc, Boulder, CO 80301, USA

ESAT ORHON, M.D., Department of Obstetrics and Gynecology, Division of Reproductive Endocrinology and Infertility, Gulhane Military Medical Academy, School of Medicine, Ankara, TURKEY

RESAD PASIC, M.D., Department of Obstetrics and Gynecology, University of Louisville School of Medicine, Louisville KY 40292, USA

Marcello Pietrantoni, M.D., Division of Maternal-Fetal Medicine, Department of Obstetrics and Gynecology, University of Louisville School of Medicine, Louisville, KY 40292, USA

LiSA M. PEACOCK, M.D., Department of Gynecology and Obstetrics, Emory University School of Medicine, Atlanta, GA 30329, USA

LOThAR W. POPP, M.D., Clinic Dr. Guth, Arzt für Gynäkologie und Geburtshilfe, 22609 Hamburg, GERMANY

DWIGHT PRIDHAM, M.D., Department of Obstetrics and Gynecology, University of Louisville School of Medicine, Louisville, KY 40292 USA

Rubén A. QuinTERO, M.D., Center for Fetal Diagnosis and Therapy, Fetal Endoscopy Program, Wayne State University, Detroit, MI 48201, USA

DAVID B. REDWINE, M.D., Endometriosis Institute of Oregon, Department of Gynecologic Surgery, St. Charles Medical Center, Bend, OR 97701, USA

HARRY REICH, M.D., Wyoming Valley GYN/OB Associates, Kingston, PA 18704, and Department of Obstetrics and Gynecology, Advanced Laparoscopic Surgery, 
Columbia University College of Physicians and Surgeons, New York, NY 10032, USA

BENJAMIN M. Rigor, M.D., Department of Anesthesiology, University of Louisville School of Medicine, Louisville KY 40292, USA

JoHN A. Rock, M.D., Department of Gynecology and Obstetrics, Emory University School of Medicine, Atlanta, GA 30329, USA

ZEV RosenwaKs, M.D., The Center for Reproductive Medicine and Infertility, The New York Hospital-Cornell Medical Center, Department of Obstetrics and Gynecology, New York, NY 10021, USA

Michael J. SAmmarco, M.D., Department of Obstetrics and Gynecology, Northwestern University Medical School, Chicago, IL 60611, USA

JOSEPH S. SANFILIPPO, M.D., Division of Reproductive Endocrinology, Department of Obstetrics and Gynecology, University of Louisville School of Medicine, Louisville, KY 40292, USA

KuRT SEMm, M.D., Klinik für Gynäkologie und Geburtshilfe, Im Klinikum der Christian-Albrechts-Univeristät und Michaelis-Hebammenschule, D-24105 Kiel, GERMANY

F. MiChael SHAW, M.D., Division of Gynecology, Westchester County Medical Center, New York Medical College, Valhalla, NY 10595, USA

STEVEN R. SMITH, Cleveland-Marshall College of Law, Cleveland, OH 44115, USA

PATRICK JAMES TAYlOR, M.D., Department of Obstetrics and Gynecology, University of British Columbia, Vancouver, B.C. V6Z 1Y6, CANADA

Howard C. Topel, M.D., Parkside Medical Center, Park Ridge, IL 60068, USA

Rafael F. VAlle, M.D., Department of Obstetrics and Gynecology, Northwestern University Medical School, Chicago, IL 60611, USA

PAUl F. VIETZ, M.D., Carroll County General Hospital, Westminster, MD 21157, USA

GARY C. VitALE, M.D., Department of Surgery, University of Louisville School of Medicine, Louisville, KY 40292, USA

WENDY K. WINER, R.N., B.S.N., Center for Women's Care and Reproductive Surgery, Atlanta, GA 30327, USA

HOWARD N. WINFIELD, M.D., Department of Urology, The University of Iowa College of Medicine, Iowa City, IA 52242-1101, USA 